

\title{
Multi-Objective Optimization in a Finite Time Thermodynamic Method for Dish-Stirling by Branch and Bound Method and MOPSO Algorithm
}

\begin{tabular}{|c|c|}
\hline Journal: & Frontiers in Energy \\
\hline Manuscript ID & FIE-2017-0053.R1 \\
\hline Manuscript Type: & Original Article \\
\hline Date Submitted by the Author: & 13-Jul-2017 \\
\hline Complete List of Authors: & $\begin{array}{l}\text { Ahmadi, Mohammad Hosein; Shahrood University of Technology } \\
\text { Nazemzadegan, Mohammadreza ; Department of Renewable Energies, } \\
\text { Faculty of New Science and Technologies, University of Tehran, Tehran, } \\
\text { Iran. } \\
\text { Kasaeian, Alibakhsh; Department of Renewable Energies, Faculty of New } \\
\text { Science and Technologies, University of Tehran, Tehran, Iran. } \\
\text { Toghyani, Somayeh; Department of Renewable Energies, Faculty of New } \\
\text { Science and Technologies, University of Tehran, Tehran, Iran. } \\
\text { Saidur, Rahman ; Faculty of Science and Technology, Sunway University, } \\
\text { No. 5, Jalan Universiti, Bandar Sunway, } 47500 \text { Petaling Jaya, Malaysia } \\
\text { Ming, Tingzhen; School of Civil Engineering and Architecture, Wuhan } \\
\text { University of Technology, Wuhan } 430070, \text { P.R.China }\end{array}$ \\
\hline Keywords: & Dish-Stirling, finite time model, branch and bound algorithm, MOPSO \\
\hline Speciality: & Renewable and new energy, Thermal engineering and power plant \\
\hline
\end{tabular}

\section{SCHOLARONE"}

Manuscripts 
Multi-Objective Optimization in a Finite Time Thermodynamic Method for Dish-Stirling by Branch and Bound Method and MOPSO Algorithm

\author{
Mohammad Reza Nazemzadegan ${ }^{1}$, Alibakhsh Kasaeian ${ }^{1}$, Somayeh Toghyani ${ }^{1}$, Mohammad \\ Hossein Ahmadi ${ }^{2 *}$, R. Saidur ${ }^{3,4}$, Tingzhen Ming ${ }^{5}$ \\ ${ }^{1}$ Department of Renewable Energies, Faculty of New Science and Technologies, University of Tehran, \\ Tehran, Iran. \\ ${ }^{2}$ Faculty of Mechanical Engineering, Shahrood University of Technology, Shahrood, Iran \\ ${ }^{3}$ Faculty of Science and Technology, Sunway University, No. 5, Jalan Universiti, Bandar Sunway, 47500 \\ Petaling Jaya, Malaysia \\ ${ }^{4}$ Department of Engineering, Lancaster University, Lancaster, LA1 4YW, UK. \\ ${ }^{5}$ School of Civil Engineering and Architecture, Wuhan University of Technology, Wuhan 430070, P.R.China \\ Email address of corresponding author: mohammadhosein.ahmadi@gmail.com
}

\begin{abstract}
There are various analyses for a solar system with the dish Stirling technology. One of those analyses is the finite time thermodynamic analysis. By the finite time thermodynamic analysis, the total power of system can be obtained by calculating the process time. In this study, the convection and radiation heat transfer losses from collector surface, the conduction heat transfer between hot and cold cylinders and cold side heat exchanger have been considered. During this investigation, the four objective functions have been optimized simultaneously. These objective functions are included of the power, efficiency, entropy and economic factors. In addition to the four-objective optimization, threeobjective, two-objective and single-objective optimizations have been done on the dishStirling model. In this study, the algorithm of MOPSO with post-expression of preferences is used for multi-objective optimizations while the Branch and Bound algorithm with Preexpression of preferences is used for single-objective and multi-objective optimizations. In case of multi-objective optimizations with post-expression of preferences, Pareto optimal front are obtained, afterward by implementing the Fuzzy, LINMAP and TOPSIS decision
\end{abstract}


making algorithms, the single optimum results can be achieved. At the end, the comparison of the results shows the benefits of MOPSO in optimizing dish Stirling finite time thermodynamic equations.

Keywords: Dish-Stirling; finite time model; branch and bound algorithm; MOPSO.

\section{Introduction}

The energy crisis and environmental concerns at the late $20^{\text {th }}$ century drew the attention of worldwide society into the fossil fuels replacements. One of the most important replacements of fossil fuels is solar energy [1]. Dish-Stirling systems by implementing solar energy in Stirling cycle are one of the most known solar systems. There are various analyses for a solar system with the dish Stirling technology. One of those analyses is the finite time analysis. The finite time models were first attained by Curzon and Ahlborn [2]. After about twenty years that this model had been utilized, some researchers questioned the applicability of the finite time models [3,4]. One of the reasons of not trusting on the finite time model is the reversibility assumption that has been considered in this model; therefore the results of the model have been different from the experimental results. In order to improve this error, a new parameter called the irreversibility factor has been developed. In some papers, including the research done by Talili [5], the benefits of this parameter was studied. In another work, carried out by Urieli, Kaushik, and Costea, this parameter has been considered in the model [6-10].

There are many researches about Stirling engines and their cycles. Wu et al. considered the regenerator and heat exchanger irreversibilities of Stirling engine. They also developed a correlation between the total output power and the thermal efficiency [11]. Petrescu et al. conducted an analysis based on the First Law of Thermodynamics with direct method and the finite speed model on a close cycle and calculated the Stirling engine power and efficiency [12]. Timoumi et al. for the purpose of increasing the Stirling engine efficiency, analyzed the second order Stirling engine and analyzed some physical and geometrical parameters in the engine efficiency [13]. Cheng et al. developed a numerical model for a Beta type Stirling engine. They considered the non-isothermal effects, the regenerator performance, and the heater thermal resistance. They also predicted the periodic changes in the pressure, volume, temperature, heat transfer, and mass transfer rates of the system [14]. Ataer studied a free-piston Stirling engine. In this model, the piston replacement parameter has been used and therefore, time has been eliminated from the equations [15]. Tlili, in one 
of his researches, maximized the output power and efficiency of an internal reversible heat engine at the maximum point of power. He considered the regenerator loss in his study [16]. Formosa and Despesse performed a thermodynamic analysis on a free-piston Stirling engine. They used the experimental data of a GPU-3 engine in their model [17]. Formosa studied a free-piston Stirling engine with a thermodynamic-dynamic semi-analytical model in another work [18]. Some researchers did different works about Stirling engines, Stirling cycles, and the dish-Stirling systems. The comparison of low and high temperature differential Stirling engines, investigation of solar collector design parameters and study of a real engine are included in these works [19-21].

Beside the analyses that have been done about Stirling engines and cycles, there are some works which show optimizing the Stirling cycles $[22,23]$. In some of these papers, the simultaneous optimizing of more than one objective function is observed. This type of optimization, that calls the multi-objective optimization, basically uses the Artificial Intelligence methods to achieve the optimum solution. One of the most popular methods used in the Stirling cycle optimizations is the Genetic algorithm [24-32]. The Genetic algorithm is a type of evolutionary algorithm. Also, some energy system optimizations have been done using the PSO methods. For example, Chaituo and Nika optimized a thermoacoustic engine [33]. In some of the optimizations, the MOPSO algorithm was used for optimizing the Stirling cycles [34, 35].

Most of the multi-objective optimizations done in the previous studies have been with post-expression of preferences, and the algorithms implemented in these studies are usually with three or less objective functions. In this investigation, four objective functions are optimized simultaneously. These objective functions include the power, efficiency, entropy, and economic factors. In addition to the four-objective optimization, the three-objective, the two-objective, and the single-objective optimizations are carried out on the dishStirling model. In this study, the algorithm of MPOSO with post-expression of preferences is used for multi-objective optimizations while the Branch and Bound algorithm with Preexpression of preferences is used for single-objective and multi-objective optimizations. In case of the multi-objective optimizations with post-expression of preferences, after obtaining the Pareto optimal front by implementing the Fuzzy, LINMAP and TOPSIS decision making algorithms, the single optimum results can be achieved.

\section{Methodology}


In the Dish-Stirling systems, parabolic mirrors reflect solar light through a collector. Collector reflects the radiation on the hot side of Stirling engine. In the present system, it is assumed that the dish is equipped with sun tracker; so at any moment, the maximum possible solar energy reaches the collector. In addition to the hot side, there is a cold side or heat sink in the Stirling engine. In this study, it is assumed that the hot side and cold side have constant temperatures.

As shown in Figure 1, the Stirling thermodynamic cycle consists of two isothermal and two constant-volume processes. In the process 1-2 a compressing working fluid at constant temperature of $T_{c}$, rejects the heat to a heat sink at constant temperature of $T_{L}$. In the process $2-3$, the working fluid crosses over the regenerator in an isochoric process and is preheated to the temperature of $T_{h}$. In the process 3-4, the working fluid receives the heat from heat source and expands through an isothermal process with temperature of $\mathrm{T}_{\mathrm{H}}$. In the process $4-1$, the working fluid cools down through a constant-volume process by the regenerator.

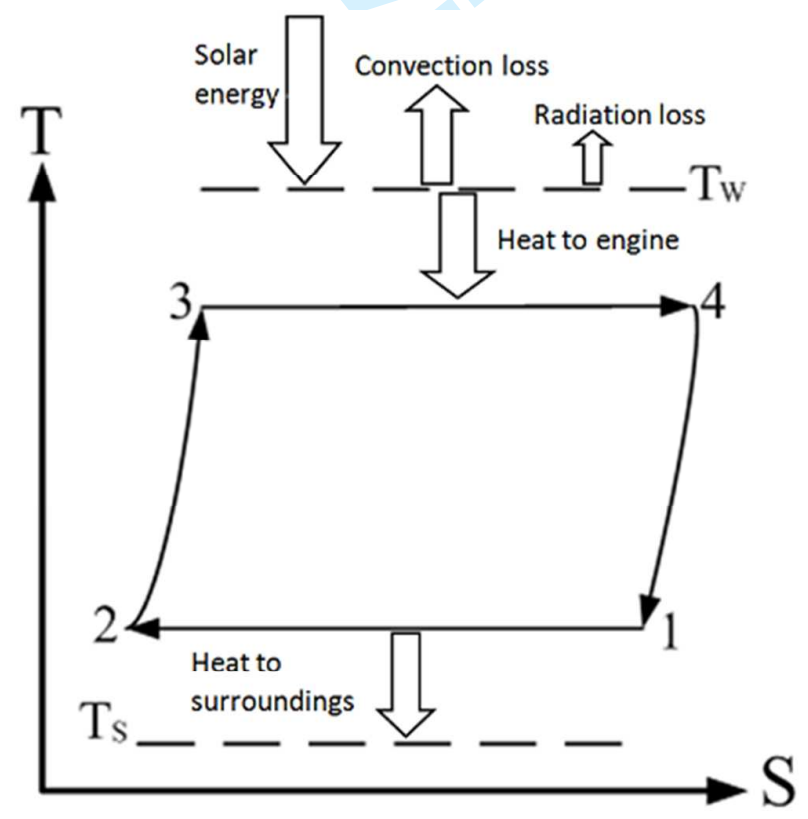

Figure 1: The Stirling thermodynamic cycle

By considering the convection and radiation heat losses, the useful received thermal energy may be calculated by Eq. (1): 
$q_{u}=I A_{\text {app }} \eta_{0}-A_{\text {rec }}\left[h\left(T_{H}-T_{0}\right)+\varepsilon \delta\left(T_{H}^{4}-T_{0}^{4}\right)\right]$

where $I$ is the direct solar flux intensity and $\mathrm{A}_{\text {app }}$ is the collector aperture area.

The thermal efficiency of the Dish-Stirling system can be calculated by Eq. (2):

$\eta_{s}=\frac{q_{u}}{I A_{\text {app }}}=\eta_{0}-\frac{1}{I C}\left[h\left(T_{H}-T_{0}\right)+\varepsilon \delta\left(T_{H}^{4}-T_{0}^{4}\right)\right]$

where $C$ is the collector concentration ratio.

The calculation of the heat transferred at the hot side and the cold side of the Stirling cycle can be done through Eqs. (3) and (4).

$Q_{h}=\left[h_{h} A_{H}\left(T_{H}-T_{h}\right)\right] t_{h}$

$Q_{c}=\left[h_{c} A_{L}\left(T_{c}-T_{L}\right)\right] t_{l}$

where, $t_{h}$ and $t_{1}$ are the duration times of the heat transfer process at the hot side and the cold side, respectively.

By implementing the thermodynamic equations and the entropy definition, the heat that is transferred at the hot side of the cycle, may be calculated by Eq. (5). Also, by considering the irreversibility factor $(\varphi)$, the rate of heat transfer at the cold side of the cycle is calculated by Eq. (6). It is worthy to mention that the irreversibility factor can be greater than or equal to one.

$$
\begin{aligned}
& Q_{34}=Q_{h}=n R T_{h} \ln \left(\frac{V_{4}}{V_{3}}\right)=n R T_{h} \ln \lambda \\
& Q_{c}=\phi n R T_{c} \ln \left(\frac{V_{1}}{V_{2}}\right)=\phi n R T_{c} \ln \lambda
\end{aligned}
$$


By simultaneously using the thermodynamic and heat transfer equations, the duration time of each Stirling cycle process can be calculated. By utilizing Eqs. (3) and (5) together, the duration time of process 3-4 may be obtained through Eqs. (7) and (8).

$\left[h_{h} A_{H}\left(T_{H}-T_{h}\right)\right] t_{h}=n R T_{h} \ln \lambda$

$t_{h}=\frac{n R T_{c} \ln \lambda}{\left[h_{h} A_{H}\left(T_{H}-T_{h}\right)\right]}$

Also, by applying Eqs. (4) and (6), the time of heat transfer at the cold side can be calculated by Eqs. (9) and (10).

$\left[h_{c} A_{L}\left(T_{c}-T_{L}\right)\right]_{l}=\phi n R T_{c} \ln \lambda$

$t_{l}=\frac{\phi n R T_{c} \ln \lambda}{\left[h_{c} A_{L}\left(T_{c}-T_{L}\right)\right]}$

In order to calculate the time of regenerator processes, the following equations can be used:

$\frac{d T}{d t}= \pm M_{i}$

In the above equation, $\mathrm{M}$ is only a function of property of the regenerator materials and called the regenerative time constant. With this regard, the time of processes 2-3 and 4-1 can be calculated by Eqs. (12) and (13).

$t_{3}=\frac{T_{h}-T_{c}}{M_{1}}$

$t_{4}=\frac{T_{h}-T_{c}}{M_{2}}$

Therefore, according to Eqs. (7) to (13), the total time of the whole thermodynamic cycle can be obtained by the following equation: 


$$
t=\frac{n R T_{h} \ln \lambda}{\left[h_{h} A_{H}\left(T_{H}-T_{h}\right)\right]}+\frac{\phi n R T_{c} \ln \lambda}{\left[h_{c} A_{L}\left(T_{c}-T_{L}\right)\right]}+\frac{T_{h}-T_{c}}{M_{1}}+\frac{T_{h}-T_{c}}{M_{2}}
$$

\subsection{Heat loss between the Stirling engine hot and cold cylinders}

Due to the low distance between the Stirling engine hot and cold cylinders, there is an undesirable conduction heat transfer between two cylinders. This heat loss can be calculated by Eq. (15).

$Q_{0}=k_{0}\left(T_{H}-T_{L}\right) t$

By considering this heat loss, the total heat removed from the heat source and the total heat absorbed by the heat sink may be estimated by Eqs. (16) and (17).

$Q_{H}=Q_{h}+Q_{0}$

$Q_{L}=Q_{c}+Q_{0}$

\subsection{The power, thermodynamic efficiency and entropy calculation}

In order to calculate the power, thermodynamic efficiency, and entropy change of the cycle, Eqs. (18) to (20) can be utilized.

$$
\begin{aligned}
& P^{\prime}=\frac{W}{t}=\frac{Q_{H}-Q_{L}}{t} \\
& \eta_{t}=\frac{Q_{H}-Q_{L}}{Q_{H}} \\
& \sigma=\frac{1}{t}\left(\frac{Q_{L}}{T_{L}}-\frac{Q_{H}}{T_{H}}\right)
\end{aligned}
$$

By implementing a variable changing as shown in Eq. (21), Eqs. (22) to (24) are achieved.

$$
F_{1}=\frac{1}{n R \ln \lambda}\left(\frac{1}{M_{1}}+\frac{1}{M_{2}}\right)
$$




$$
\begin{aligned}
& P^{\prime}=\frac{T_{h}-\phi T_{c}}{\left(\frac{T_{h}}{\left[h_{h} A_{H}\left(T_{H}-T_{h}\right)\right]}+\frac{\phi T_{c}}{\left[h_{c} A_{L}\left(T_{c}-T_{L}\right)\right]}+F_{1}\left(T_{h}-T_{c}\right)\right)} \\
& \eta_{t}=\frac{T_{h}-\phi T_{c}}{T_{h}+k_{0}\left(T_{H}-T_{L}\right)\left(\frac{T_{h}}{\left[h_{h} A_{H}\left(T_{H}-T_{h}\right)\right]}+\frac{\phi T_{c}}{\left[h_{c} A_{L}\left(T_{c}-T_{L}\right)\right]}+F_{1}\left(T_{h}-T_{c}\right)\right)} \\
& \sigma=\frac{\left(\frac{\phi T_{c}}{T_{L}}-\frac{T_{h}}{T_{H}}\right)}{\left(\frac{T_{h}}{\left[h_{h} A_{H}\left(T_{H}-T_{h}\right)\right]}+\frac{\phi T_{c}}{\left[h_{c} A_{L}\left(T_{c}-T_{L}\right)\right]}+F_{1}\left(T_{h}-T_{c}\right)\right)}
\end{aligned}
$$

Also, by utilizing two new parameters as $x=\left(T c / T_{h}\right)$ and $A_{R}=\left(A_{L} / A_{H}\right)$, the power, efficiency, and entropy change may be obtained by Eqs. (25) to (27).

$$
\begin{aligned}
& P^{\prime}=\frac{1-\phi x}{\left(\frac{1}{\left[h_{h} A_{H}\left(T_{H}-T_{h}\right)\right]}+\frac{\phi x}{\left[h_{c} A_{R} A_{H}\left(x T_{h}-T_{L}\right)\right]}+F_{1}(1-x)\right)} \\
& \eta_{t}=\frac{1-\phi x}{1+k_{0}\left(T_{H}-T_{L}\right)\left(\frac{1}{\left[h_{h} A_{H}\left(T_{H}-T_{h}\right)\right]}+\frac{\phi x}{\left[h_{c} A_{R} A_{H}\left(x T_{h}-T_{L}\right)\right]}+F_{1}(1-x)\right)} \\
& \sigma=\frac{\left(\frac{\phi x}{T_{L}}-\frac{1}{T_{H}}\right)}{\left(\frac{1}{\left[h_{h} A_{H}\left(T_{H}-T_{h}\right)\right]}+\frac{\phi x}{\left[h_{c} A_{R} A_{H}\left(x T_{h}-T_{L}\right)\right]}+F_{1}(1-x)\right)}
\end{aligned}
$$

By having the thermal efficiency of the solar mirror and the thermodynamic efficiency of the Stirling engine, the total efficiency of the dish-Stirling system can be achieved by Eq. (28).

$\eta_{m}=\eta_{t} \eta_{s}$

\subsection{Economic factor}


The economic factor in the dish-Stirling equations shows the power output of the system per unit of investment cost. This definition actually has been replaced with the definition of power per unit of fuel in many energy systems; but since there is no fuel in a solar system, the economic factor has been defined [30]. The economic factor is described by Eq. (29) as follows:

$F^{\prime}=\frac{P^{\prime}}{C_{a i}}$

The investment cost of the dish-Stirling system itself is a function of the heat transfer area of the hot and cold sides of the cycle [30]. This function is shown in Eq. (30).

$C_{a i}=a A_{H}+b A_{L}$

\subsection{Objective Functions}

By substituting Eqs. (25) to (30) in Eq. (29) and utilizing the following variable changing, Eq. (32) can be driven. Also by implementing some variable changes as Eqs. (33) to (35), finally the dimensionless objective functions can be achieved as Eqs. (36) to (39).

$z=\frac{a}{a+b}$

$F^{\prime}=\frac{1-\phi x}{a\left(\frac{1+\left(\frac{1-z}{z}\right) A_{R}}{\left[h_{h}\left(T_{H}-T_{h}\right)\right]}+\frac{\phi x\left(1+\left(\frac{1-z}{z}\right) A_{R}\right)}{\left[h_{c} A_{R}\left(x T_{h}-T_{L}\right)\right]}+F_{1}(1-x)\left(1+\left(\frac{1-z}{z}\right) A_{R} A_{H}\right)\right)}$

$f=\frac{a F^{\prime}}{h_{h} T_{L}}$

$P=\frac{P^{\prime}}{h_{h} A_{h} T_{L}}$ 


$$
\begin{aligned}
& S=\frac{\sigma}{h_{h} A_{h} T_{L}} \\
& f=\frac{1+\left(\frac{1-z}{z}\right) A_{R}}{T_{L}\left(\frac{\phi x h_{h}\left(1+\left(\frac{1-z}{z}\right) A_{R}\right)}{\left(T_{H}-T_{h}\right)}+\frac{1-\phi x}{h_{c} A_{R}\left(x T_{h}-T_{L}\right)}+F_{1} h_{h} A_{H}(1-x)\left(1+\left(\frac{1-z}{z}\right) A_{R}\right)\right)} \\
& P=\frac{1-\phi x}{T_{L}\left(\frac{1}{\left(T_{H}-T_{h}\right)}+\frac{\phi x h_{h}}{h_{c} A_{R}\left(x T_{h}-T_{L}\right)}+F_{1} h_{h} A_{H}(1-x)\right)} \\
& \eta_{m}=\left(\eta_{0}-\frac{1}{I C}\left[h\left(T_{H}-T_{0}\right)+\varepsilon \delta\left(T_{H}^{4}-T_{0}^{4}\right)\right]\right) \\
& 1+k_{0}\left(T_{H}-T_{L}\right)\left(\frac{1}{\left[h_{h} A_{H}\left(T_{H}-T_{h}\right)\right]}+\frac{1-\phi x}{\left[h_{c} A_{R} A_{H}\left(x T_{h}-T_{L}\right)\right]}+F_{1}(1-x)\right) \\
& S=\frac{\left(\frac{\phi x}{T_{L}}-\frac{1}{T_{H}}\right)}{\phi x h_{h}}\left(\frac{1}{\left(T_{H}-T_{h}\right)}+\frac{T_{c} A_{R}\left(x T_{h}-T_{L}\right)}{h_{1}}+F_{1} h_{h} A_{H}(1-x)\right)
\end{aligned}
$$

\section{Variables constraints}

After achieving the dimensionless objective functions, next step is to specify the decision variables ranges. According to the final form of the objective functions, the decision variables consist of $\varphi$ (internal irreversibility factor), $A_{R}$ (cold side area to hot side area ratio of Stirling cycle), $\mathrm{x}$ (cold temperature to hot temperature ratio of working fluid), $T_{H}$ (hot side temperature of the cycle) and $\mathrm{T}_{h}$ (hot temperature of working fluid). These variables are the most important variables from the system operation point of view. Afterward, all other parameters values will be specified.

The optimization will be done with the following constraints. Eqs. (40) to (44) show the variable constraints. 
$\phi \geq 1$

$0.45 \leq x \leq 0.7$

$0.25 \leq A_{R} \leq 10$

$1100 \leq T_{H} \leq 1400$

$850 \leq T_{h} \leq 1000$

\section{Multi-Objective Optimization}

There are various definitions for multi-objective optimization in economy and engineering; but there are some common basic concepts in all of its definitions. Some of these basic concepts consist of the preferences, the utility function, and the Pareto optimal front [36$38]$.

- Preferences: It is about preferences of decision maker about choosing the optimum point. There are two main types of preferences in multi-objective optimization. One preference is taken into consideration in the objective function before optimization e.g. by inserting some coefficient into objective functions and adding the objective functions to each other and creating a main objective function, the so called utility function. In this paper this type of preference is called as the pre-expression of preferences. In the other type, decision making process is utilized after achieving the results. In this step, there is not a single point as the optimum point; but a series of non-dominated points make a frontier, which is called as the Pareto frontier or the Pareto optimal front. So, by implementing an appropriate decision making algorithm which applies the preferences of decision maker, the single optimum point will be achieved. In this paper, this type of preference is called as the postexpression of preferences.

- Utility function: It considers the decision maker satisfaction. In pre-expression of preferences multi-objective optimization, one utility function is defined for each objective function that shows the related importance of each objective function. The combination of utility functions makes the main utility function. 
- Pareto optimal front: In post-expression of preferences multi-objective optimization, the first step results are a series of points. The Pareto optimal front includes a group of those points, so called non-dominated points. The non-dominated points are the points that, in comparison with every other point at least at one objective function, are closer to the optimum result of that objective function. By implementing the decision making algorithms at the Pareto frontier, the ultimate optimum result can be achieved.

\subsection{Particle swarm optimization algorithm}

The particle swarm algorithm was first introduced by Kennedy and Eberhart [39]. The beginning of this algorithm is inspired by the studies done on the birds and fishes movements in groups. According to the studies, the movements of each fish in its group are affected by best pervious movements of its own and every other fishes in the group; where the best movement, means for example closer approach to the food. Therefore there is a direct or indirect relation between the movements of each fish in the group. By passing the time and repeating the movements, finally all of the fishes are closer to the food, in comparison to first movements.

For the particle swarm algorithm there is also a similar procedure. In the particle swarm optimization (PSO) a random group of particles are chosen and each particle represents one point in the result area for each point, there is a memory using which the point can move in regard with its previous best position and the best positions of all other particles. At the end, by enough iteration, the best position of particles can be at an acceptable neighborhood of the optimum point.

The best previous position of each particle is called personal optimum and the best previous position of all particles is called the overall optimum. If a movement and a position vector for each particle is considered, the next movement vector and the next position vector of each point would be driven by influence of these four factors:

1- Present position vector

2- Present movement vector

3- Difference between present position vector and the personal optimum

4- Difference between present position vector and the overall optimum 


\section{Decision making algorithms}

As mentioned before, the results of multi-objective optimizations with post-expression of preferences make the Pareto optimal front. After developing the Pareto frontier, by utilizing decision making algorithms, the ultimate optimum point would be achieved. In order to obtain the optimum result, there are so many decision making algorithms, but three most popular of these algorithms are Fuzzy, TOPSIS and LINMAP. In this study these three decision making algorithms have been considered.

Before implementing the decision making algorithms into the Pareto frontier, the results of previous step of optimization should be non-dimensionalized. Two non-dimentionalization methods are described here.

- Linear non-dimensionalization

The results of multi-objective optimization are vectors with more than one dimension. The number of dimensions of multi-objective optimization results is as many as the number of objective functions. If a point of Pareto frontier is presented by $F_{i j}$, where $i$ is index for each point and $j$ is index for each objective function, so the linear non-dimensionalization algorithm for a point when its objective is maximizing or minimizing is shown by Eqs. (45) and (46), respectively.

$$
\begin{aligned}
& F_{i j}^{\text {norm }}=\frac{F_{i j}}{\max _{i}\left(F_{i j}\right)} \\
& F_{i j}^{\text {norm }}=\frac{F_{i j}}{\max _{i}\left(\frac{1}{F_{i j}}\right)}
\end{aligned}
$$

- Fuzzy non-dimensionalization

In this method for each point of $F_{i j}$, the distance to the ideal is divided by the distance between ideal point and non-ideal point. The ideal point is the point in where all of the objective functions are optimum and the non-ideal point is the point in where all of the objective functions are the worst possible amount. According to that, in the multi-objective optimization, the results have been achieved by try and error so the worst possible amount of each objective has a specific value. The Fuzzy non-dimensionalization of point $F_{i j}$ can be calculated by Eq. (47). 


$$
F_{i j}^{\text {norm }}=\frac{F_{i j}-F_{i j}^{\text {nonideal }}}{F_{i j}^{i d e a l}-F_{i j}^{n o n i d e a l}}
$$

\subsection{Fuzzy decision making method}

In this method the dimensionless values that are non-dimensionalized by the fuzzy method, are utilized. As mentioned before, in the non-dimensionalization step, there is a corresponding dimensionless point for any point at the Pareto frontier. In the fuzzy decision making method, for each dimensionless point of $F_{i j}$, the optimum point is achieved by following equation:

$$
F_{\text {OptFuzzy }}=F_{i j} ; \max _{i}\left[\min _{j}\left(\frac{F_{i j}-F_{i j}^{\text {nonideal }}}{F_{i j}^{\text {ideal }}-F_{i j}^{\text {nonideal }}}\right)\right]
$$

\subsection{LINMAP decision making algorithm}

The basic of this method is about finding a point among the Pareto optimal front that is closest to the ideal point. This method can be shown by Eq. (49):

$$
F_{\text {OptLinmap }}=F_{i j} ; \min \left(\left|F^{\text {Ideal }}-F\right|\right)
$$

\subsection{TOPSIS decision making algorithm}

This algorithm is based on finding a point at the Pareto frontier that has the least distance to the ideal point and the most distance to the non-ideal point. In fact this is the point whose distance to the ideal point minus its distance to the non-ideal point is minimum in comparison to all other Pareto points. This method can be shown by Eq.(50):

$$
F_{\text {OptTopsis }}=F_{i j} ; \min \left(\left|F^{\text {Ideal }}-F\right|-\left|F^{\text {nonIdeal }}-F\right|\right)
$$

Afterward, first the set values of parameters will be specified and then the results of optimizations of dish-Stirling system will be presented.

\section{Optimization parameters}

With the purpose of optimization of the dish-Stirling model, the values of constant parameters should be specified. In order to have consistency with previous studies, the specific value of parameters are considered as followings $[22,30]$ : 
$\mathrm{h}_{\mathrm{h}}=\mathrm{h}_{\mathrm{c}}=200 \quad \mathrm{WK}^{-1} \mathrm{~m}^{-2}, \mathrm{f}=0.7, \mathrm{C}=1300, \delta=5.67 \mathrm{e}-8 \quad \mathrm{WK}^{-4} \mathrm{~m}^{-2}, \mathrm{~T}_{\mathrm{L}}=300 \mathrm{~K}, \mathrm{~h}=20 \quad \mathrm{WK}^{-1} \mathrm{~m}^{-2}$, $\mathrm{I}=1000 \quad \mathrm{Wm}^{-2}, \quad\left(1 / \mathrm{M}_{1}+1 / \mathrm{M}_{2}\right)=2 \mathrm{e}-5 \quad \mathrm{~s} . \mathrm{K}^{-1}, \quad \mathrm{R}=8.3 \quad \mathrm{Jmol}^{-1} \mathrm{~K}^{-1}, \quad \mathrm{n}=1 \quad \mathrm{~mol}, \quad \lambda=2, \quad \varepsilon=0.9$, $\mathrm{k}_{0}=2.5 \mathrm{WK}^{-1}, \eta_{0}=0.85$

\section{Results and Discussion}

As it was mentioned before, at the present study, the dish-Stirling model is solved in cases of single-objective and multi-objective optimizations. In case of multi-objective optimizations, there are two types of pre-expression and post-expression of preferences. In case of optimization with pre-expression of preferences, there is a four-objective optimization. But in case of optimization with post-expression of preferences, there appear two-objective, three-objective and four-objective optimizations. Finally, the results of all these optimizations are presented.

\subsection{Results of single-objective optimization}

For each one of four objective functions, there is an optimum point. In order to optimize each objective function, the branch and bound optimization algorithm has been utilized. The branch and bound algorithm is a non-linear optimization. Table 1 shows the optimum results for each objective function together with corresponding values of other objective functions.

Table 1: Results of single-objective optimization

\begin{tabular}{|c|c|c|c|c|c|c|c|c|c|}
\hline & \multicolumn{5}{|c|}{ Decision Variables } & \multicolumn{4}{|c|}{ Objectives } \\
\hline & $\varphi$ & $\mathrm{x}$ & $A_{R}$ & $\mathrm{~T}_{\mathrm{H}}$ & $\mathrm{T}_{\mathrm{h}}$ & $\mathrm{f}$ & $\mathrm{P}$ & $\eta$ & $\mathrm{S}$ \\
\hline $\operatorname{Max}(f)$ & 1.000 & 0.478 & 1.491 & $\begin{array}{c}1400 . \\
0\end{array}$ & $\begin{array}{c}998.2 \\
90\end{array}$ & 0.190 & 0.312 & 0.333 & 0.000465 \\
\hline $\operatorname{Max}(\mathrm{P})$ & 1.000 & 0.475 & 10.000 & $\begin{array}{c}1400 . \\
0\end{array}$ & $\begin{array}{c}850.0 \\
00\end{array}$ & 0.100 & 0.531 & 0.344 & 0.000790 \\
\hline $\operatorname{Max}(\eta)$ & 1.000 & 0.450 & 10.000 & $\begin{array}{c}1100 . \\
0\end{array}$ & $\begin{array}{c}850.0 \\
00\end{array}$ & 0.060 & 0.315 & 0.408 & 0.000285 \\
\hline $\operatorname{Min}(S)$ & 1.000 & 0.450 & 0.250 & $\begin{array}{c}1100 . \\
0\end{array}$ & $\begin{array}{c}850.0 \\
00\end{array}$ & 0.046 & 0.051 & 0.323 & 0.000046 \\
\hline
\end{tabular}

7.2.Results offour-objective optimization with pre-expression of preferences 
By using the branch and bound algorithm in order to solve the four-objective optimization with pre-expression of preferences, the results of optimization of the dish-Stirling model are presented in Table 2.

Table 2: Results of four-objective optimization with pre-expression of preferences

\begin{tabular}{ccccc|crrr}
\multicolumn{3}{c}{ Decision Variables } & \multicolumn{4}{c}{ Objectives } \\
\hline$\varphi$ & $\mathrm{x}$ & $\mathrm{A}_{\mathrm{R}}$ & $\mathrm{T}_{\mathrm{H}}$ & $\mathrm{T}_{\mathrm{h}}$ & $\mathrm{f}$ & $\mathrm{P}$ & $\eta$ & $\mathrm{S}$ \\
\hline 1.000 & 0.450 & 10.000 & 1400.0 & 876.6 & 0.100 & 0.528 & 0.36 & 0.000665 \\
\hline
\end{tabular}

In this optimization, each of four objective functions have a proportional weight to their optimum value.

\subsection{Results of multi-objective optimization with post-expression of preferences}

As mentioned before, in case of optimization with post-expression of preferences, there are two-objective, three-objective, and four-objective optimizations.

- Four-objective optimization results

Since there are four objective functions, the results of this optimization are vectors with four dimensions; so the results cannot be shown in a chart and due to the great number of results, just the ultimate optimum result is presented in this case. The ultimate result, achieved by each one of the decision making methods, is presented in Table 3.

Table 3: Results of four-objective optimization with post-expression of preferences

\begin{tabular}{|c|c|c|c|c|c|c|c|c|c|}
\hline & \multicolumn{5}{|c|}{ Decision Variables } & \multicolumn{4}{|c|}{ Objectives } \\
\hline & $\varphi$ & $\mathrm{x}$ & $A_{R}$ & $\mathrm{~T}_{\mathrm{H}}$ & $\mathrm{T}_{\mathrm{h}}$ & $f$ & $P$ & $\eta$ & $\mathrm{S}$ \\
\hline Fuzzy & 1.003 & 0.4602 & 2.0689 & 1292.4 & 949.096 & 0.155 & 0.339 & 0.373 & 0.000395 \\
\hline Linmap & 1.0026 & 0.4802 & 4.1062 & 1391.2 & 907.0816 & 0.172 & 0.332 & 0.363 & 0.000401 \\
\hline Topsis & 1.0411 & 0.4603 & 2.9210 & 1349.7 & 931.4148 & 0.183 & 0.337 & 0.351 & 0.000423 \\
\hline
\end{tabular}

According to the results of four-objective optimization, at the ultimate optimal point, the dimensionless power is in the range of 0.33 to 0.34 and the thermal efficiency falls in the range of 0.35 to 0.37 . Among the decision making algorithms, the Fuzzy algorithm has picked an optimal point with the best thermal efficiency and slightly more optimum 
entropy. In the other hand, an optimal point with a better economical factor has been chosen by the TOPSIS algorithm.

- Three-objective optimization results

By having four objective functions, there could be four optimizations of three-objective optimization. So the Pareto frontier and ultimate optimum results of each three-objective optimization is presented by Figs. 2-5 and Tables 3-6. In the Result section, the figures represent the corresponding Pareto frontier. In the figures the non-dominating points, the ideal point, the non-ideal point, and the ultimate optimal point, chosen by the decision making algorithms, have been shown. Also the tables of this section represent the optimal objective functions and their corresponding decision variables chosen by various decision making algorithms.

The results of the economic factor, the power and the thermal efficiency of the threeobjective optimization are shown in Fig. 2 and Table 4. According to these results. In comparison with other decision making methods, the Fuzzy algorithm, the LINMAP algorithm, and the TOPSIS algorithm have reached to the best thermal efficiency, power, and economic factor, respectively.

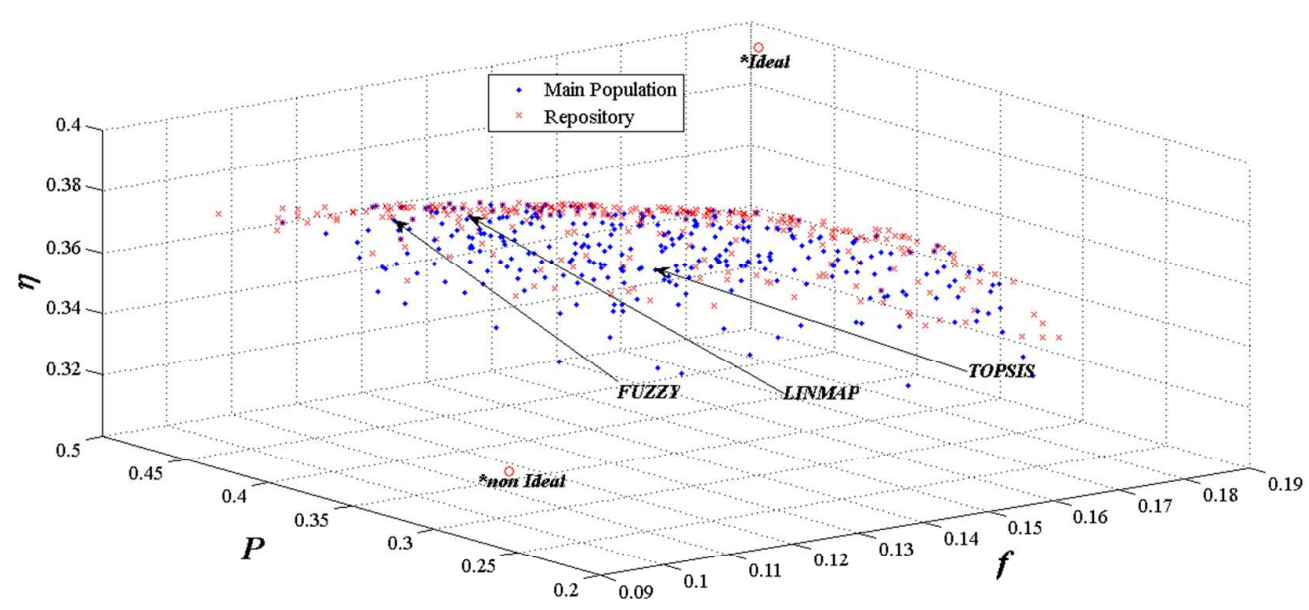

Figure 2: Pareto frontier of three-objective (f, P, $\eta$ ) optimization with post-expression of preferences 
Table 4: Results of three-objective (f, $\mathrm{P}, \eta)$ optimization with post-expression of preferences

\begin{tabular}{c|ccccc|crr}
\hline \multicolumn{4}{c}{} & \multicolumn{4}{c|}{ Decision Variables } & \multicolumn{3}{c}{ Objectives } \\
\cline { 2 - 10 } \multicolumn{2}{c}{$\varphi$} & $\mathrm{x}$ & $\mathrm{A}_{\mathrm{R}}$ & $\mathrm{T}_{\mathrm{H}}$ & $\mathrm{T}_{\mathrm{h}}$ & $\mathrm{f}$ & $\mathrm{P}$ & $\eta$ \\
\hline Fuzzy & 1.0019 & 0.452 & 3.232 & 1286.2 & 932.82 & 0.145 & 0.423 & 0.364 \\
LINMAP & 1.0026 & 0.468 & 6.396 & 1310.2 & 897.80 & 0.158 & 0.431 & 0.355 \\
TOPSIS & 1.0303 & 0.475 & 5.061 & 1364.9 & 929.26 & 0.177 & 0.384 & 0.348 \\
\hline
\end{tabular}

Fig. 3 and Table 5 show the results of the economic factor, the power, and the entropy of the three-objective optimization. The interesting point in these results is that the LINMAP and the TOPSIS algorithms both have obtained a similar optimal point.

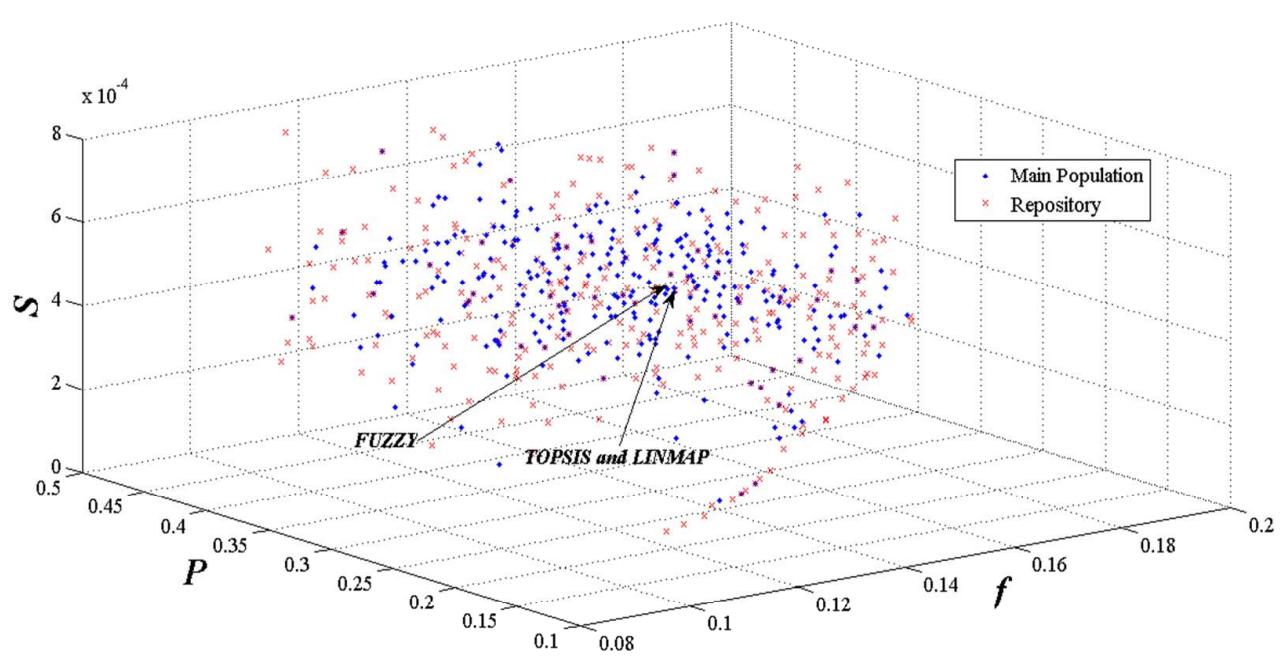

Figure 3: Pareto frontier of three-objective (f, P, S) optimization with post-expression of preferences

Table 5: Results of three-objective (f, P, S) optimization with post-expression of preferences

\begin{tabular}{cccccc|cccc}
\hline \multicolumn{4}{c|}{ Decision Variables } & & \multicolumn{3}{c}{ Objectives } \\
\cline { 2 - 8 } & $\mathrm{x}$ & $\mathrm{A}_{\mathrm{R}}$ & $\mathrm{T}_{\mathrm{H}}$ & $\mathrm{T}_{\mathrm{h}}$ & $\mathrm{f}$ & $\mathrm{P}$ & $\mathrm{S}$ \\
\hline
\end{tabular}




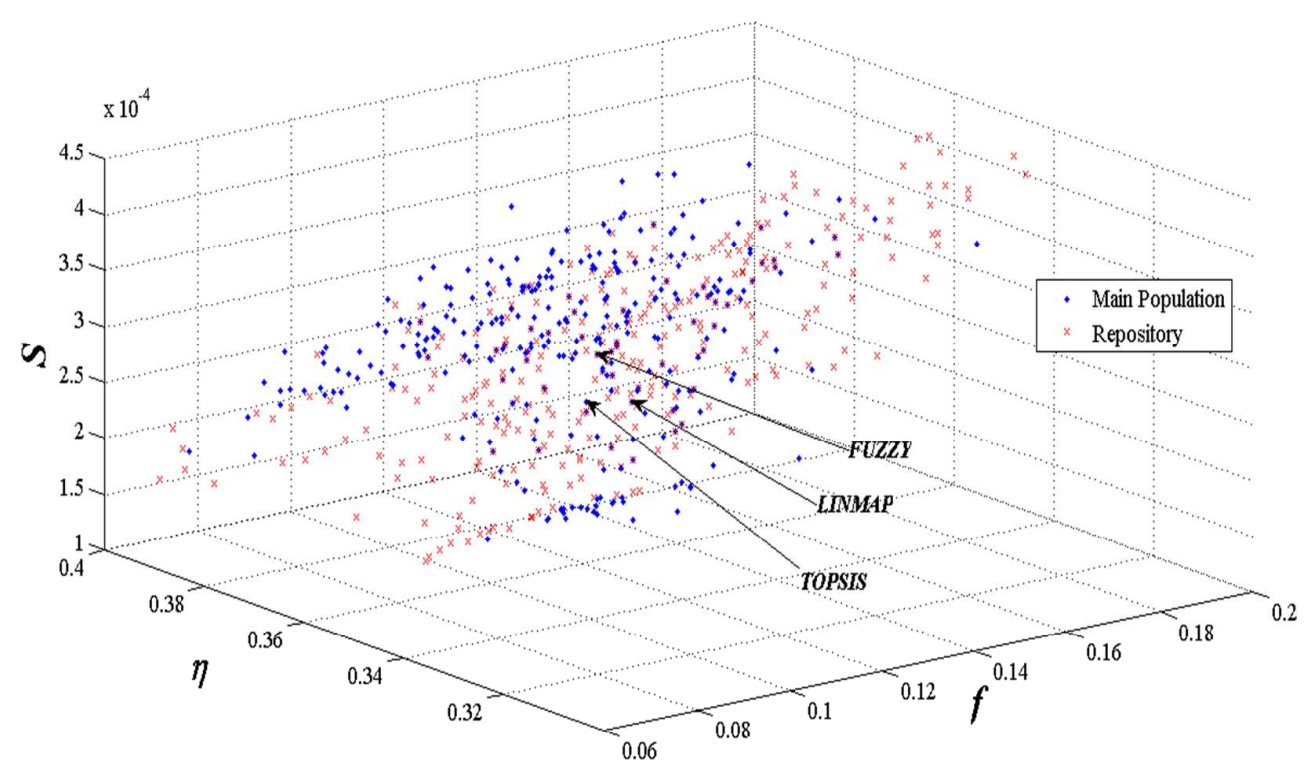

Figure 4: Pareto frontier of three-objective (f, $\eta, S$ ) optimization with post-expression of preferences

Table 6: Results of three-objective (f, $\eta, S$ ) optimization with post-expression of preferences

\begin{tabular}{c|ccccc|ccc}
\hline \multicolumn{4}{c}{} & \multicolumn{4}{c|}{ Decision Variables } & \multicolumn{3}{c}{ Objectives } \\
\cline { 2 - 10 } & $\varphi$ & $\mathrm{x}$ & $\mathrm{A}_{\mathrm{R}}$ & $\mathrm{T}_{\mathrm{H}}$ & $\mathrm{T}$ & $\mathrm{f}$ & $\eta$ & $\mathrm{S}$ \\
\hline Fuzzy & 1.0027 & 0.4750 & 2.4029 & 1229.5 & 974.21 & 0.1430 & 0.3784 & 0.000237 \\
Linmap & 1.0171 & 0.4504 & 1.4500 & 1214.7 & 948.59 & 0.1426 & 0.3640 & 0.000213 \\
Topsis & 1.0014 & 0.4542 & 3.9563 & 1139.6 & 984.06 & 0.1415 & 0.3608 & 0.00208 \\
\hline
\end{tabular}


Fig. 5 and Table 7 represent the results of the power, the thermal efficiency, and the entropy of the three-objective optimization. The optimal points that have been selected by the Topsis and the Linmap decision making algorithms are exactly the same. While the Fuzzy algorithm has achieved an optimal point with a slightly better entropy, but it has a worse power function.

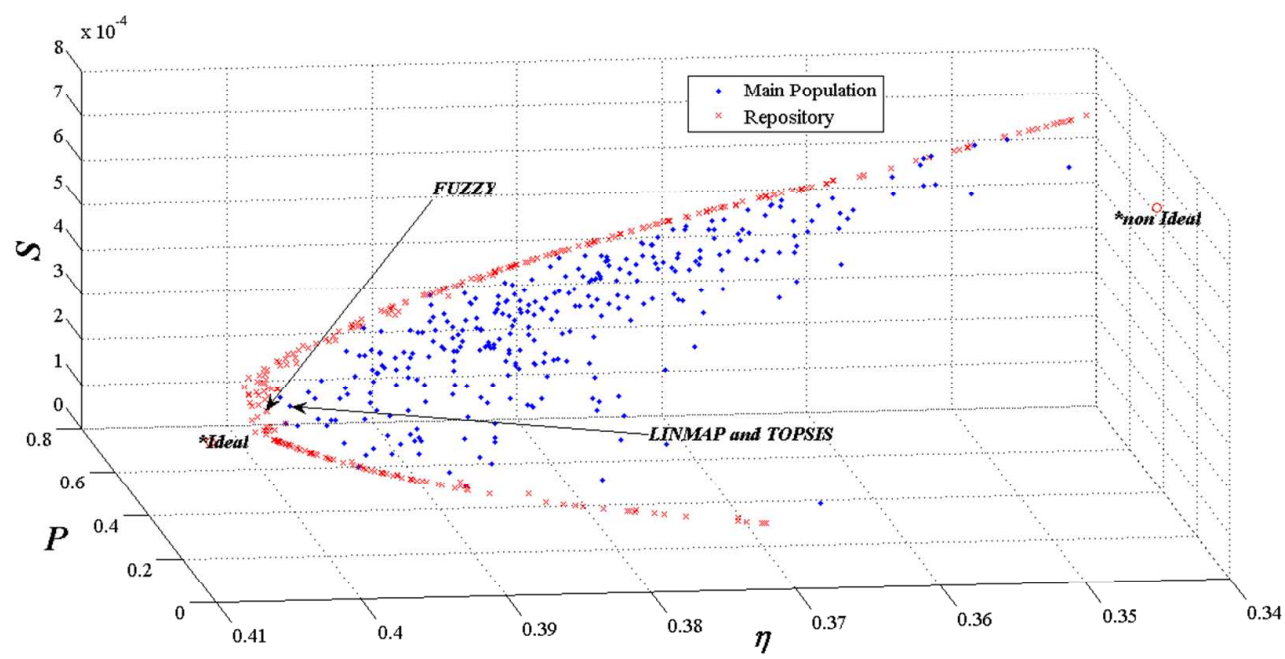

Figure 5: Pareto frontier of three-objective $(\mathrm{P}, \eta, \mathrm{S})$ optimization with post-expression of preferences

Table 7: Results of three-objective $(\mathrm{P}, \eta, \mathrm{S})$ optimization with post-expression of preferences

\begin{tabular}{|c|c|c|c|c|c|c|c|c|}
\hline & \multicolumn{5}{|c|}{ Decision Variables } & \multicolumn{3}{|c|}{ Objectives } \\
\hline & $\Phi$ & $\mathrm{x}$ & $A_{R}$ & $\mathrm{~T}_{\mathrm{H}}$ & $\mathrm{T}_{\mathrm{h}}$ & $\mathrm{P}$ & $\eta$ & S \\
\hline Fuzzy & 1.0054 & 0.4504 & 6.4309 & 1128.7 & 868.23 & 0.309 & 0.407 & 0.000280 \\
\hline Linmap & 1.0008 & 0.4503 & 7.9711 & 1137.7 & 850.00 & 0.315 & 0.407 & 0.000285 \\
\hline Topsis & 1.0008 & 0.4503 & 7.9711 & 1137.7 & 850.00 & 0.315 & 0.407 & 0.000285 \\
\hline
\end{tabular}

- Two-objective optimization results

By having four objective functions, there could be six optimizations with two-objectives. So the Pareto frontier and the ultimate optimum results of each two-objective optimization are presented in Figs. 6-11 and Tables 8-13. 
The results of the economic factor and the power of the two-objective optimization are shown in Fig. 6 and Table 8. According to these results, the Fuzzy decision making algorithm has reached to an optimal point with a higher power and the TOPSIS algorithm has reached a point with higher economical factor. As shown in Table 8, in comparison with the other decision making algorithms, the optimal point chosen by the LINMAP algorithm is at higher heat source temperature and lower heat sink temperature.

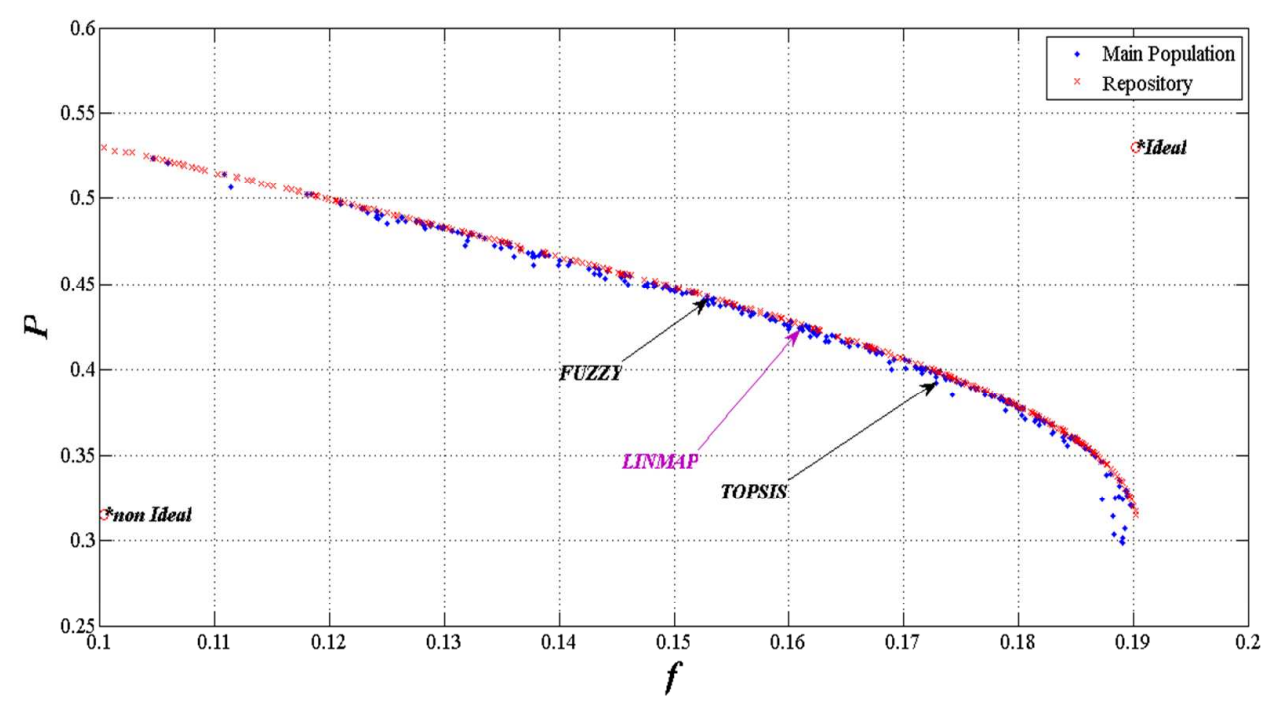

Figure 6: Pareto frontier of two-objective (f, P) optimization with post-expression of preferences

Table 8: Results of two-objective ( $\mathrm{f}, \mathrm{P}$ ) optimization with post-expression of preferences

\begin{tabular}{c|ccccc|cc}
\hline & \multicolumn{5}{c|}{ Decision Variables } & \multicolumn{2}{c}{ Objectives } \\
\cline { 2 - 9 } \multicolumn{1}{c}{$\varphi$} & \multicolumn{1}{c}{$\mathrm{x}$} & $\mathrm{A}_{\mathrm{R}}$ & $\mathrm{T}_{\mathrm{H}}$ & $\mathrm{T}_{\mathrm{h}}$ & $\mathrm{f}$ & $\mathrm{P}$ \\
\hline Fuzzy & 1.0000 & 0.4726 & 3.0483 & 1399.9 & 945.86 & 0.1533 & 0.4423 \\
LINMAP & 1.0005 & 0.4836 & 4.1740 & 1400.0 & 929.26 & 0.1609 & 0.4275 \\
TOPSIS & 1.0002 & 0.4605 & 1.9859 & 1399.9 & 977.11 & 0.1738 & 0.3973 \\
\hline
\end{tabular}

In Fig. 7 and Table 9 the results of the economic factor and the thermal efficiency of the two-objective optimization are presented. Among the results of three decision making algorithms, the ultimate optimal point of Fuzzy algorithm shows a better thermal efficiency but a lower economic factor, in comparison to the TOPSIS and the LINMAP algorithms. This optimal point has been in a lower amounts of $\mathrm{x}$ and $\mathrm{A}_{\mathrm{R}}$ decision variable. 


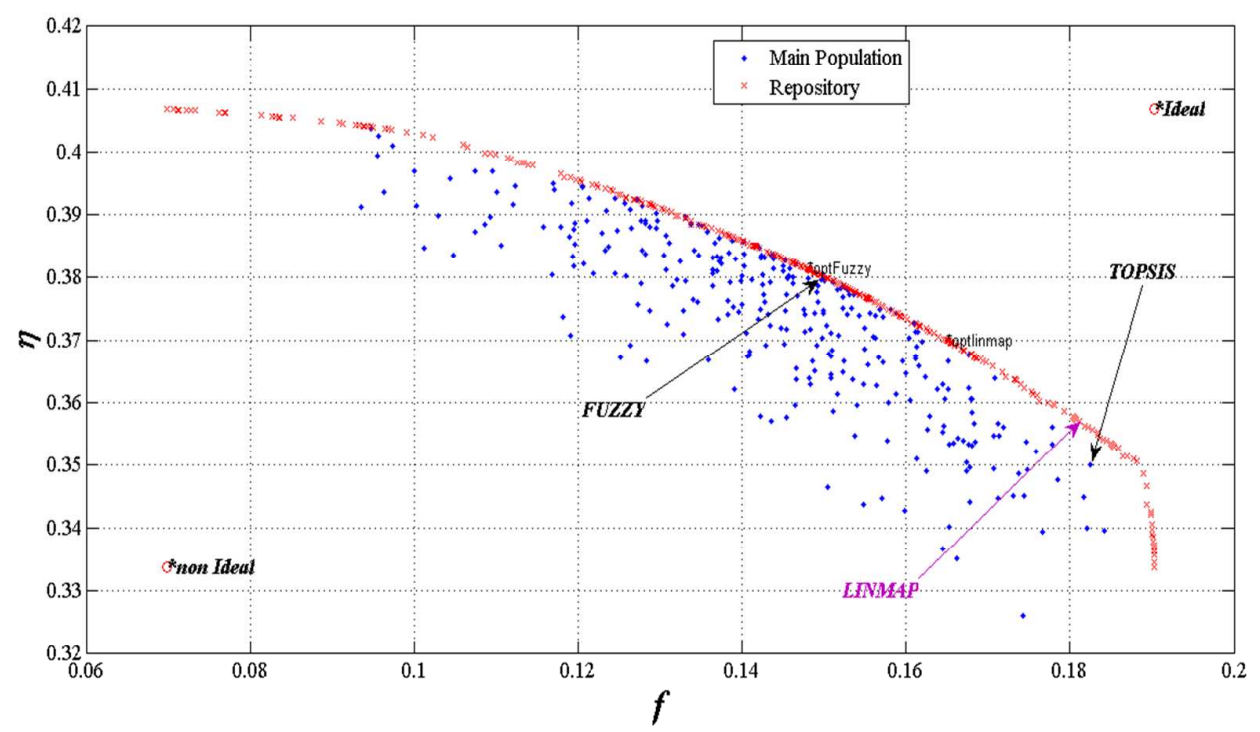

Figure 7: Pareto frontier of two-objective (f, $\eta$ ) optimization with post-expression of preferences

Table 9: Results of two-objective (f, $\eta$ ) optimization with post-expression of preferences

\begin{tabular}{|c|c|c|c|c|c|c|c|}
\hline & \multicolumn{5}{|c|}{ Decision Variables } & \multicolumn{2}{|c|}{ Objectives } \\
\hline & $\varphi$ & $\mathrm{x}$ & $A_{R}$ & $\mathrm{~T}_{\mathrm{H}}$ & $\mathrm{T}_{\mathrm{h}}$ & $f$ & $\eta$ \\
\hline Fuzzy & 1.0003 & 0.4584 & 1.7197 & 1252.4 & 934.53 & 0.1500 & 0.3799 \\
\hline LINMAP & 1.0005 & 0.4801 & 3.3165 & 1284.5 & 940.28 & 0.1812 & 0.3571 \\
\hline TOPSIS & 1.0002 & 0.4750 & 3.0802 & 1326.8 & 965.14 & 0.1883 & 0.3507 \\
\hline
\end{tabular}

Fig. 8 and Table 10 show the results of the power and the thermal efficiency of the twoobjective optimization. Along with these results, in comparison with other decision making algorithms, the Fuzzy algorithm obtains an ultimate optimal with a better thermal efficiency but lower power. On the other hand, the TOPSIS algorithm obtains an optimal point with a power objective function near to the single-objective optimal of the power function. 


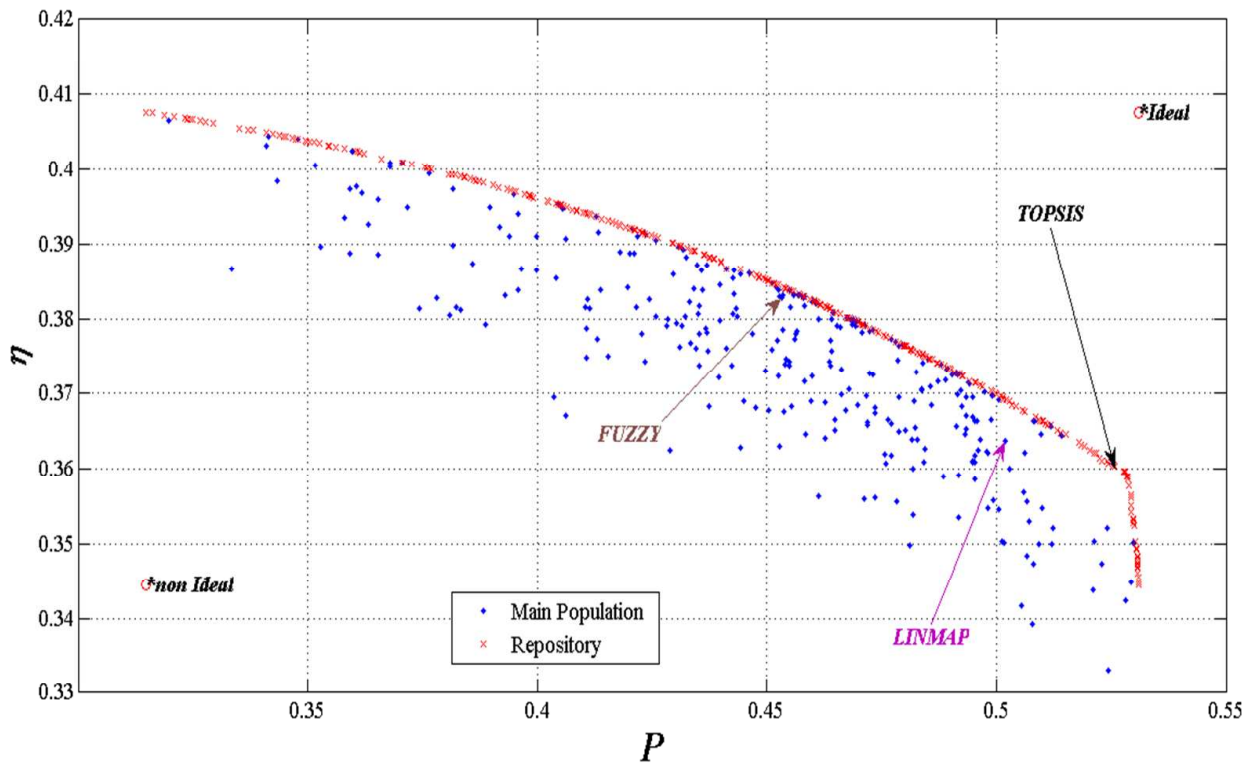

Figure 8: Pareto frontier of two-objective $(P, \eta)$ optimization with post-expression of preferences

Table 10: Results of two-objective (P, $\eta$ ) optimization with post-expression of preferences

\begin{tabular}{c|ccccc|cc}
\hline & \multicolumn{4}{c|}{ Decision Variables } & \multicolumn{3}{c}{ Objectives } \\
\cline { 2 - 9 } \multicolumn{1}{c}{$\varphi$} & $\mathrm{x}$ & $\mathrm{A}_{\mathrm{R}}$ & $\mathrm{T}_{\mathrm{H}}$ & $\mathrm{T}_{\mathrm{h}}$ & $\mathrm{P}$ & $\eta$ \\
\hline Fuzzy & 1.0001 & 0.4520 & 9.9352 & 1152.3 & 852.47 & 0.4523 & 0.3845 \\
LINMAP & 1.0000 & 0.4542 & 9.9471 & 1299.5 & 858.50 & 0.5074 & 0.3674 \\
TOPSIS & 1.0000 & 0.4500 & 9.9586 & 1264.8 & 850.00 & 0.5283 & 0.3596 \\
\hline
\end{tabular}

The results of the economic factor and the entropy of the two-objective optimization are represented in Fig 9 and Table 11. The results show that the Fuzzy decision making algorithm has selected a point with a better economic factor in comparison with the TOPSIS algorithm that reaches a point with a lower entropy changes. 


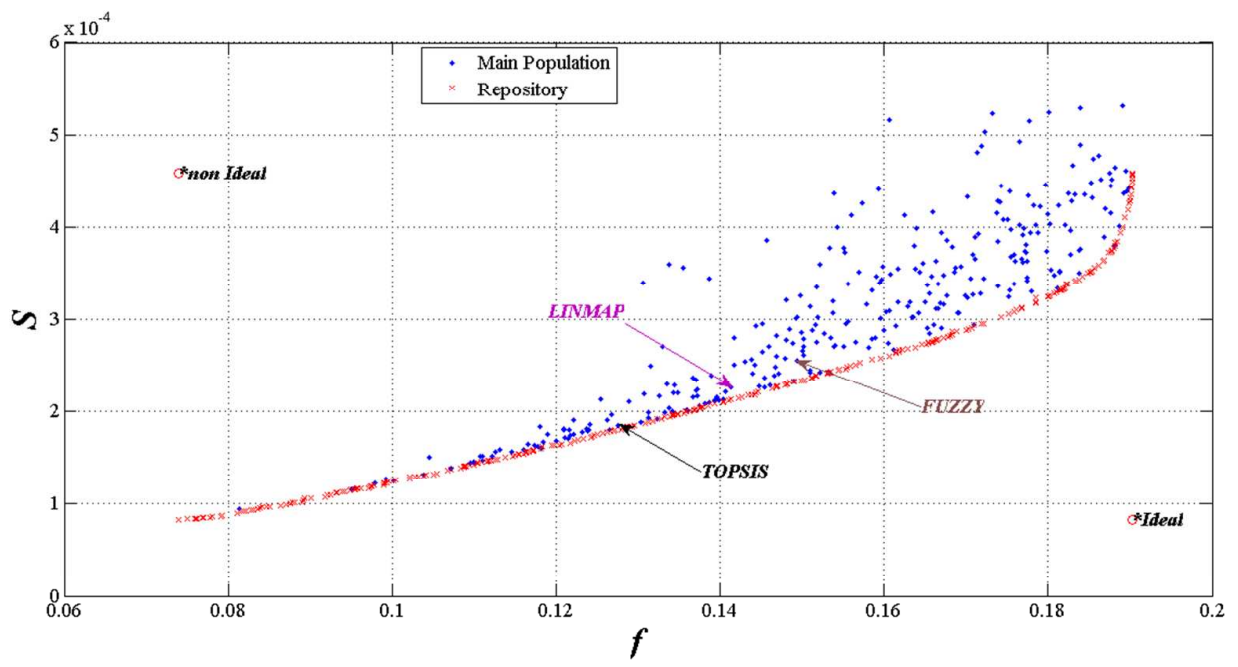

Figure 9: Pareto frontier of two-objective (f, S) optimization with post-expression of preferences

Table 11: Results of two-objective (f, S) optimization with post-expression of preferences

\begin{tabular}{c|ccccc|cc}
\hline & \multicolumn{4}{c|}{ Decision Variables } & \multicolumn{3}{c}{ Objectives } \\
\cline { 2 - 9 } & $\varphi$ & $\mathrm{x}$ & $\mathrm{A}_{\mathrm{R}}$ & $\mathrm{T}_{\mathrm{H}}$ & $\mathrm{T}_{\mathrm{h}}$ & $\mathrm{f}$ & $\mathrm{S}$ \\
\hline Fuzzy & 1.0079 & 0.4500 & 0.7250 & 1240.2 & 984.29 & 0.1520 & 0.000235 \\
LINMAP & 1.0000 & 0.4519 & 0.5000 & 1276.9 & 960.01 & 0.1425 & 0.000211 \\
TOPSIS & 1.0007 & 0.4523 & 1.4500 & 1262.3 & 955.29 & 0.1275 & 0.000175 \\
\hline
\end{tabular}

According to figure10 and table 12 which show the results of a two-objective optimization of the power and entropy, in order to reach the optimal point, all of the three decision making algorithms have reached to a point with an about maximum $A_{R}$ (the cold side heat transfer area to the hot side heat transfer area). In comparison with other decision making algorithms, the Fuzzy algorithm has selected an optimal point with a higher power and the TOPSIS algorithm has opted a point with a better entropy change. 


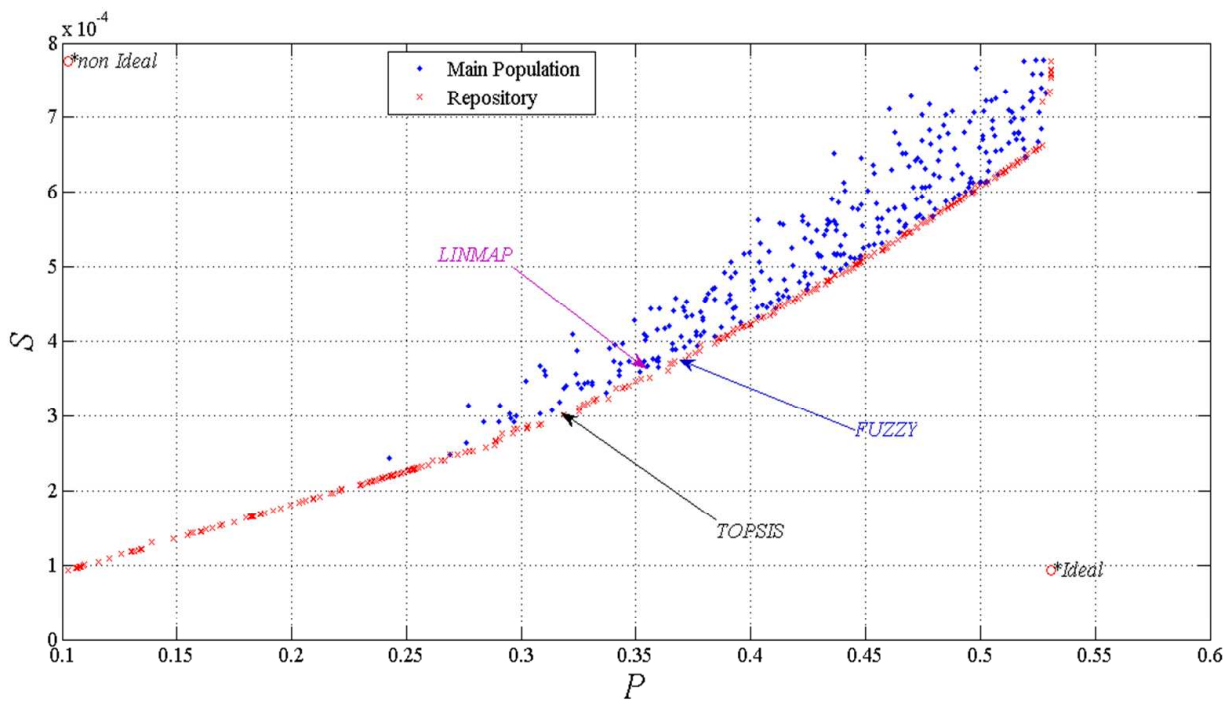

Figure 10: Pareto frontier of two-objective $(\mathrm{P}, \mathrm{S})$ optimization with post-expression of preferences

Table 12: Results of two-objective (P, S) optimization with post-expression of preferences

\begin{tabular}{c|ccccc|crc}
\hline & \multicolumn{4}{c|}{ Decision Variables } & \multicolumn{3}{c}{ Objectives } \\
\cline { 2 - 8 } & $\varphi$ & $\mathrm{x}$ & $\mathrm{A}_{\mathrm{R}}$ & $\mathrm{T}_{\mathrm{H}}$ & $\mathrm{T}_{\mathrm{h}}$ & & $\mathrm{P}$ & $\mathrm{S}$ \\
\hline Fuzzy & 1.0005 & 0.4816 & 9.6704 & 1339.3 & 857.53 & 0.3790 & 0.000391 \\
LINMAP & 1.0000 & 0.4711 & 9.3228 & 1209.7 & 865.87 & 0.3571 & 0.000358 \\
TOPSIS & 1.0059 & 0.4929 & 10.0000 & 1377.8 & 850.00 & 0.3227 & 0.000308 \\
\hline
\end{tabular}

Fig. 11 and Table 13 represent the results of the thermal efficiency and the thermal efficiency of the two-objective optimization. The results show that the ultimate optimal points have been obtained at almost the minimum of $\mathrm{x}$ (the hot side temperature to the cold side temperature of the cycle), $\mathrm{T}_{\mathrm{h}}$ (the hot side temperature) and $\mathrm{T}_{\mathrm{H}}$ (the heat source temperature). According to Table 13, the Fuzzy decision making algorithm has chosen a point with a higher thermal efficiency and the TOPSIS algorithm has selected a point with a better entropy change. 


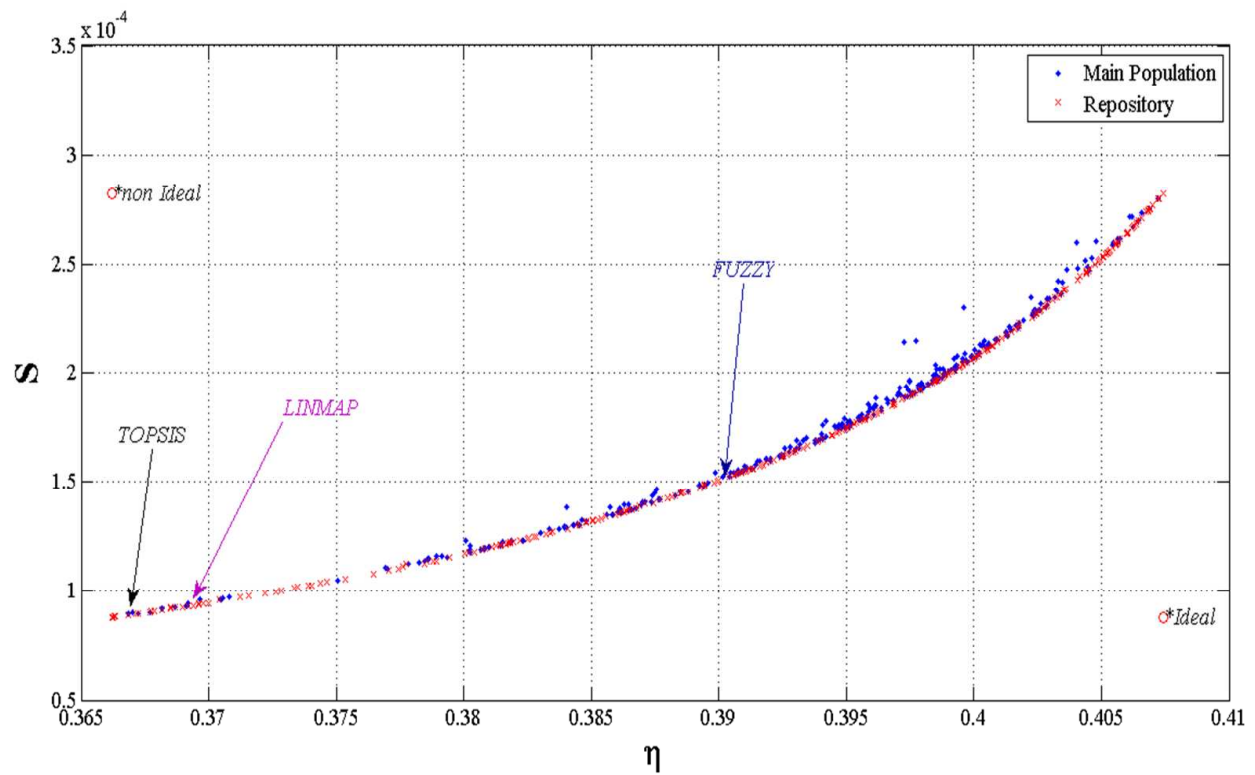

Figure 11: Pareto frontier of two-objective $(\eta, S)$ optimization with post-expression of preferences

Table 13: Results of two-objective $(\eta, S)$ optimization with post-expression of preferences

\begin{tabular}{c|ccccc|cc}
\hline & \multicolumn{4}{c|}{ Decision Variables } & \multicolumn{2}{c}{ Objectives } \\
\cline { 2 - 9 } & $\varphi$ & $\mathrm{x}$ & $\mathrm{A}_{\mathrm{R}}$ & $\mathrm{T}_{\mathrm{H}}$ & $\mathrm{T}_{\mathrm{h}}$ & & $\mathrm{S}$ \\
\hline Fuzzy & 1.0000 & 0.4502 & 1.9978 & 1100.2 & 853.18 & 0.3903 & 0.000152 \\
LINMAP & 1.0000 & 0.4500 & 2.5461 & 1100.6 & 865.72 & 0.3686 & 0.000092 \\
TOPSIS & 1.0005 & 0.4502 & 4.5771 & 1100.9 & 859.37 & 0.3618 & 0.000118 \\
\hline
\end{tabular}

\subsection{Validation}

Among the various optimization have done in this work, some optimization have been done in some other papers and so the results of these paper optimizations can be verified with some references. According to the single-objective optimization results, in order to achieve the optimal thermal efficiency, the heat source temperature should be about 1100 ${ }^{\circ} \mathrm{C}$. As shown in the Fig 12, similar results were reported in $[22,23]$ in a wide range of the concentration ratio. In addition, among the decision variables, $\mathrm{x}$ (the hot side temperature to the cold side temperature of the cycle) is in a range of 0.45 to 0.50 that can be verified by the results of references [23, 25]. Fig 13 shows the range of the optimum point for variable $\mathrm{x}$. 


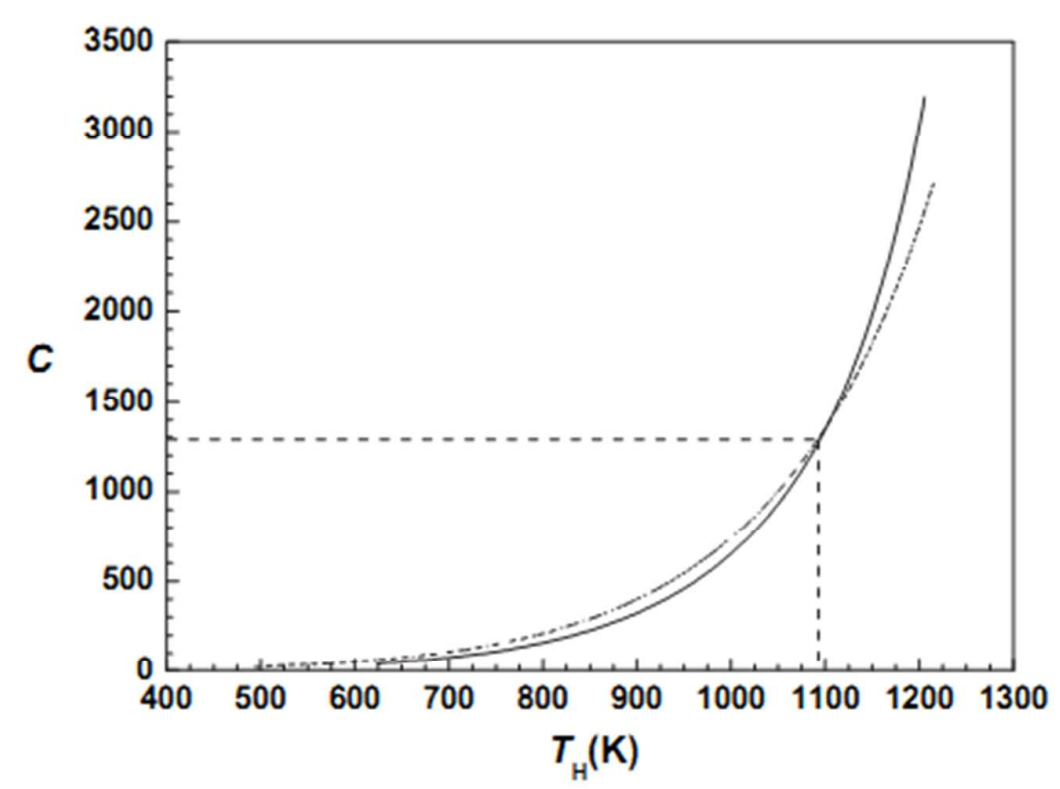

Figure 12: The optimum absorber temperature and the concentrating ratio of the system [22].

\begin{abstract}
Also, as shown in Fig. 13, the optimal thermal efficiency results obtained through various multi-objective optimizations in this research are in a range of 0.35 to $0.41 \%$ that is a valid range for a Stirling cycle thermal efficiency [30].
\end{abstract}

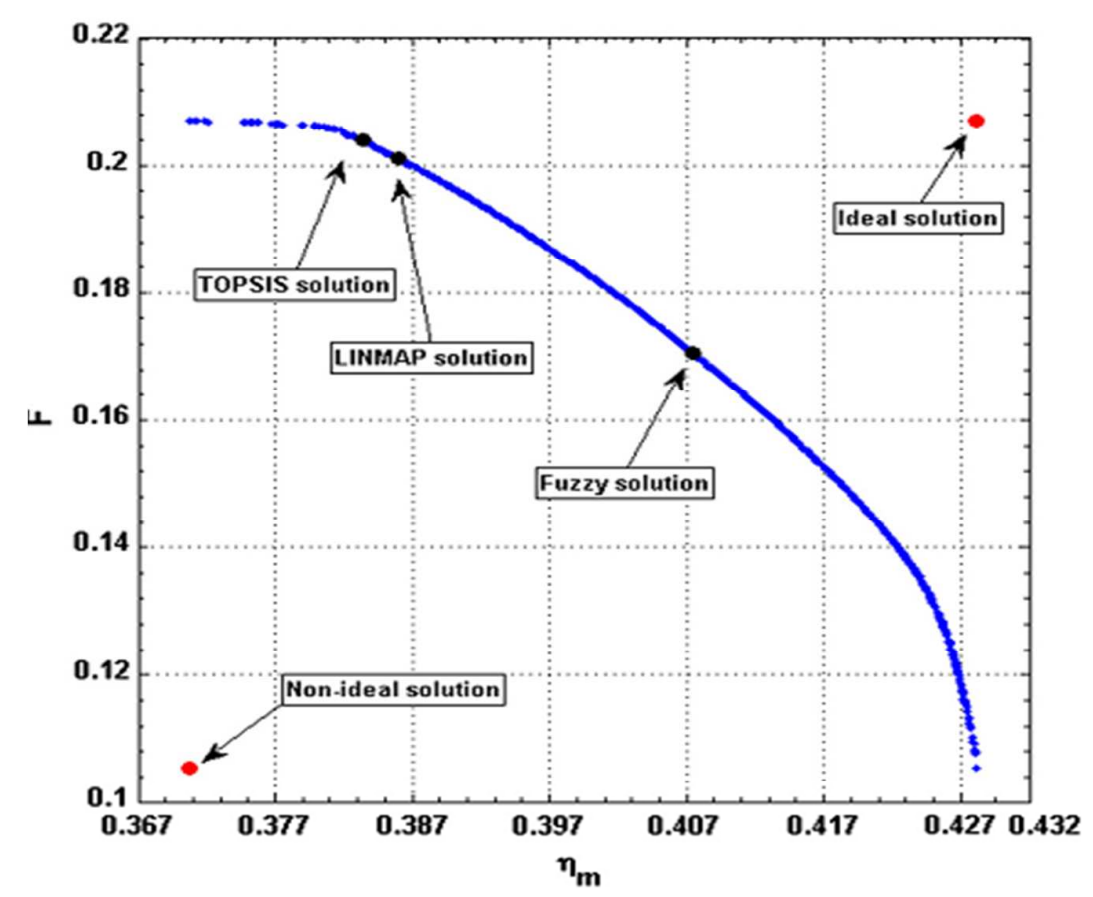

https://mc.manuscriptcentral.com/fie 
Figure 13: Pareto optimal frontier in objectives' space (thermal efficiency - dimensionless objective function)

So the validation can be presented in brief as shown in table. 14 .

Table 14: verification of decision variables of $\mathrm{x}$ and $\mathrm{T}_{\mathrm{H}}$ and $[22,30]$

\begin{tabular}{|c|c|c|}
\hline $\begin{array}{l}\text { Decision variable or } \\
\text { Objective function }\end{array}$ & $\begin{array}{l}\text { In this } \\
\text { paper }\end{array}$ & $\begin{array}{l}\text { In the } \\
\text { references }\end{array}$ \\
\hline $\mathrm{T}_{\mathrm{H}}$ & 1100 & 1100 \\
\hline$\eta_{\mathrm{m}}$ & $\begin{array}{c}0.35<< \\
0.40\end{array}$ & $\begin{array}{c}0.37<< \\
0.41\end{array}$ \\
\hline
\end{tabular}

It also shows that, with a finite time analysis of a dish-Stirling cycle and by implementing the irreversibility factor, the MOPSO multi-objective optimization can lead to an acceptable series of results, which represent the characteristics of a real system.

\section{Conclusion}

For the first time in a dish-Stirling finite time analysis, a four-objective optimization of the economic factor, the power, the thermal efficiency and the entropy change are implemented and for optimization, the MOPSO algorithm has been used. A various series of results can be achieved by series of the multi-objective optimizations done in this research. According to the results of the four-objective optimization at the ultimate optimal point, the dimensionless power is in the range of 0.33 to 0.34 and the thermal efficiency is opted in the range of 0.35 to 0.37 . Among the decision making methods, the Fuzzy method has chosen an optimal point with the best thermal efficiency and slightly more optimum entropy. While an optimal point with a better economical factor has been obtained by the TOPSIS method. In this investigation, the results of the single-objective and multiobjective optimization of the dish-Stirling cycle can be a reference for further works. In 
addition, the adaptation of the results with the practical works demonstrates the applicability of finite time analysis at estimating a dish-Stirling system performance.

\section{Acknowledgment}

This research was supported by the Scientific Research Foundation of Wuhan University of Technology (No. 40120237), the ESI Discipline Promotion Foundation of WUT (No.35400664).

\section{References}

[1] EIA. International Energy outlook; 2011.

[2] Curzon F.L, Ahlborn B. Efficiency of a Carnot engine at maximum power output. Am J Phys, 1975; 43:22-4.

[3] Moran M.J. On second law analysis and the failed promises of finite time thermodynamics. Energy 1998; 23:517-9.

[4] Gyftopulous E.P. Fundamentals of analysis of processes. Energy Conversion and Management 1997; 38:1525-33.

[5] Tlili I, Timoumi Y, Nasrallah S.B., Thermodynamic analysis of the Stirling heat engine with regenerative losses and internal irreversibilities. Int. J. of Engine Res. 2008;9(1):4556.

[6] Kaushik SC, Kumar S. Finite time thermodynamic evaluation of irreversible Ericsson and Stirling heat engines. Energy Convers Manage 2001;42:295-312.

[7] Kaushik SC, Kumar S. Finite time thermodynamic analysis of endoreversible Stirling heat engine with regenerative losses. Energy 2000;25:989-1003.

[8] Kaushik SC, Tyagi SK, Mohan S. Performance evaluation of irreversible Stirling and Ericsson heat engines. Int J Ambient Energy 2003;24:149-56.

[9] Costea M, Petrecu S, Harman C. The effect of irreversibilities on solar Stirling engine cycle performance / Energy Conversion \& Management 1999;40:1723-1731

[10] Urieli I, Kushnir M. The ideal adiabatic cycle-a rational basis for Stirling engine analysis, 17th IECEC; 1982. p. 162-8.

[11] Wu F, Chen L, Wu C, Sun F. Optimum performance of irreversible Stirlingengine with imperfect regeneration. Energy Convers Manage 1998;39:727-32.

[12] Petrescu S, Costea M, Harman C, Florea T. Application of the direct method to irreversible Stirling cycles with finite speed. Int J Energy Res 2002;26:589-609 
[13] Timoumi Y, Tlili I, Nasrallah SB. Design and performance optimization of GPU- 3 Stirling engines. Energy 2008;33(7):1100-14.

[14] Cheng $\mathrm{CH}, \mathrm{Yu}$ YJ. Numerical model for predicting thermodynamic cycle and thermal efficiency of a beta-type Stirling engine with rhombic-drive mechanism. Renew Energy 2010;35:2590-601.

[15] Ataer OE. Numerical analysis of regenerators of piston type Stirling engines using Lagrangian formulation. Int J Refrig 2002;25:640-52.

[16] Tlili I. Finite time thermodynamic evaluation of endoreversible Stirling heat engine at maximum power conditions. Renew Sustain Energy Rev 2012;16(4):2234-41

[17] Formosa F, Despesse G. Analytical model for Stirling cycle machine design Energy Convers Manage 2010;51:1855-63.

[18] Formosa F. Coupled thermodynamic-dynamic semi-analytical model of free piston Stirling engines. Energy Convers Manage 2011;52(5):2098-109.

[19] Iwamoto I, Toda K, Hirata K, Takeuchi M, Yamamoto T. Comparison of low and high temperature differential Stirling engines. In: Proceedings of the 8th International Stirling engine conference, Anacona, Italy; 1997. p. 29-38.

[20] Ahmadi MH, Hosseinzade H. Investigation of solar collector design parameters effect onto solar Stirling engine efficiency. ApplMechEng 2012;1:1-4.

[21] Erbay LB, Yavuz H. Analysis of Stirling heat engine at maximum power conditions. Energy 1997;22(7):645-50.

[22] YaqiL, Yalling H, Weiwei W. Optimization of solar-powered Stirling heat engine with fi nite-time thermodynamics / Renewable Energy 2011;36:421-427

[23] Sharma A, Shukla SK, Rai AK. Finite time thermodynamic analysis and optimization of Solar-Dish Stirling heat engine with regenerative losses. ThermSci 2011;15(4):995-1009.

[24] Sayyaadi H. Multi-objective approach in thermoenvironomic optimization of a benchmark cogeneration system / Applied Energy 2009;86:867-879

[25] AhmadiM.H, Sayyaadi H, Dehghani S, Hosseinzade H. Designing a solar powered Stirling heat engine based on multiple criteria: Maximized thermal efficiency and power / Energy Conversion and Management 2013;75:282-291

[26] Chen C, Ho C, Yau H. Performance analysis and optimization of a solar powered Stirling engine with heat transfer considerations. Energies 2012;5:3573-85.

[27] Jafari S, Mohammadi B, Boroujerdi A.A. Multi-objective optimization of a Stirling-type pulse tube refrigerator / Cryogenics 2013;55-56:53-62

[28]Ahmadi M.H, Mohammadi A.H, Dehghani S, Barranco-Jiménez M. Multi-objective thermodynamic-based optimization of output power of Solar Dish-Stirling engine by 
implementing an evolutionary algorithm / Energy Conversion and Management 2013;75:438-445

[29] Ahmadi M.H, Hosseinzade H, Sayyaadi H, Mohammadi A.H, Kimiaghalam F. Application of the multi-objective optimization method for designing a powered Stirling $g$ heat engine: Design with maximized power, thermal efficiency and minimized pressure loss / Renewable Energy 2013;60:313-322

[30] AhmadiM.H, Sayyaadi H, Mohammadi A.H, Barranco-Jiménez M. Thermo-economic multi-objective optimization of solar dish-Stirling engine by implementing evolutionary algorithm / Energy Conversion and Management 73 (2013) 370-380

[31] ] Lazzaretto A, Toffolo A. Energy, economy and environment as objectives in multicriterion optimization of thermal systems design. Energy 2002;27:549-567

[32] AhmadiM.H, AhmadiM.A, Mohammadi A.H, Feidt M. Multi-objective optimization of an irreversible Stirling cryogenic refrigerator cycle / Energy Conversion and Management 2014;82:351-360

[33] Chaitou H, Nika P.Exergetic optimization of a thermoacoustic engine using the particle swarm optimization method / Energy Conversion and Management 2012;55:71-80

[34] DuanC, Wang X, Shu S, Jing C, Chang H. Thermodynamic design of Stirling engine using multi-objective particle swarm optimization algorithm / Energy Conversion and Management 2014;84:88-96

[35] ToghyaniS, Kasaeian A, Ahmadi M.H. Multi-objective optimization of Stirling engine using non-ideal adiabatic method / Energy Conversion and Management 2014;80:54-62

[36] Ahmadi, Mohammad H., Mehdi Mehrpooya, and Fathollah Pourfayaz. "Exergoeconomic analysis and multi objective optimization of performance of a Carbon dioxide power cycle driven by geothermal energy with liquefied natural gas as its heat sink." Energy Conversion and Management 119 (2016): 422-434.

[37] Ahmadi, Mohammad Hossein, Mohammad Ali Ahmadi, Adel Mellit, Fathollah Pourfayaz, and Michel Feidt. "Thermodynamic analysis and multi objective optimization of performance of solar dish Stirling engine by the centrality of entransy and entropy generation." International Journal of Electrical Power \& Energy Systems 78 (2016): 8895.

[38] Ahmadi, Mohammad H., Mohammad-Ali Ahmadi, and Michel Feidt. "Thermodynamic analysis and evolutionary algorithm based on multi-objective optimization of performance for irreversible four-temperature-level refrigeration." Mechanics \& Industry 16, no. 2 (2015): 207.

[39] Kennedy, J., Eberhart, R. "Particle Swarm Optimization," Proceeding of International Conference on Neural Networks. Perth, Australia, 1995 IEEE, Piscataway, 1995, pp. 1942-1948. 


\section{Nomenclature}

\section{$A_{\text {res }} \quad$ absorber area}

A aperture area

app

C concentration ratio

F dimensionless objective function

f dimensionless economic factor

h heat transfer coefficient, $\mathrm{W} \mathrm{K}^{-4}$ or $\mathrm{W} \mathrm{m} \mathrm{m}^{-2} \mathrm{~K}^{-1}$

I direct solar flux intensity, $\mathrm{W} \mathrm{m}^{-2}$,

i ith objective

$\mathrm{j} \quad \mathrm{j}$ th solution

$\mathrm{n} \quad$ mole number of the working fluid, mol t cyclic period, $\mathrm{s}$

$\mathrm{x}$ temperature ratio of the Stirling engine

Greek letter

$\lambda$ ratio of volume during the regenerative processes

$\eta \quad$ thermal efficiency

$\epsilon \quad$ emissivity factor

$\sigma \quad$ Entropy

$\delta \quad$ Stefan-Boltzmann coefficient

Subscripts

H absorber (heater)( 


\section{Page 33 of 36}

Frontiers in Energy

1

2

3

4

5

6

7

8

9

10

11

12

13

14

15

16

17

18

19

20

21

22

23

24

25

26

27

28

29

30

31

32

33

34

35

36

37

38

39

40

41

42

43

44

45

46

47

48

49

50

51

52

53

54

55

56

57

58

59

60

\begin{tabular}{|llll|}
\hline $\mathrm{P}$ & dimensionless output power & $\mathrm{h}$ & high temperature side heat exchanger \\
$\mathrm{Q}$ & heat transfer, $\mathrm{J}$ & $\mathrm{L}$ & heat sink \\
$\mathrm{R}$ & universal gas constant, $\mathrm{J} \mathrm{mol}^{-1} \mathrm{~K}^{-1}$ & $\mathrm{c}$ & low temperature side heat exchanger \\
$\mathrm{S}$ & dimensionless Entropy & $\mathrm{m}$ & entire solar dish Stirling system \\
$\mathrm{T}$ & Temperature, $\mathrm{K}$ & $\mathrm{t}$ & Stirling engine \\
$\mathrm{W}$ & work, $\mathrm{J}$ & 0 & Ambient condition, optics \\
$\mathrm{V}$ & Volume & $1-4$ & process states \\
\hline
\end{tabular}


27 May 2017

\section{Dear Prof. Zhen Huang:}

We would like to thank you and the respected anonymous reviewers for their critical, but valuable and fair review and comments which substantially improved the quality of our manuscript. All of the concerns brought up by you and the reviewers are now addressed in the revised version of the paper. Further clarifications are also made accordingly in various sections of the manuscript. We list below the actions we have taken as per the reviewers' recommendation. As you will see, we have taken all suggestions into consideration and hope that the manuscript is now in a form acceptable to the high standards of your journal.

Sincerely,

MH Ahmadi

This manuscript can be accepted for publication after minor revisions, see the followings:

1. Page 3, Line45, "One of the reasons of not trusting on the finite time model is the reversibility assumption that has been considered in this model; therefore the results of the model have been different from the experimental results. In order to improve this error, a new parameter called the irreversibility factor has been developed" should be "One of the reasons of not trusting on the finite time model is the endoreversibility assumption that has been considered in this model; therefore the results of the model have been different from the experimental results. In order to improve this deviation, a new parameter called the irreversibility factor has been developed"

Reply: Thanks for your useful comments. All required changes are applied.

2. Page 4, line108, "an isothermal process with temperature of $\mathrm{T}_{\mathrm{H}}$ " should be "an isothermal process with temperature of $\mathrm{T}_{\mathrm{h}}$ ";

Reply: Thanks for your useful comments. Required change is applied.

3. Pages 4 and 5, in Figure 1, the temperatures of heat reservoirs were denoted by $T_{w}$ and $T_{s}$, while in the text and equations, they were denoted by $T_{H}$ and $T_{L}$, such as Equations (1)-(4), (7), (8), .... They should be unified.

Reply: Thanks for your useful comments. All required changes are applied.

4. Page 5, line121, " $t_{l}$ " should be " $t$ ";

Reply: Thanks for your useful comments. Required changes is applied.

5. Page 9, Equations (22)-(24), " $\mathrm{A}_{\mathrm{R}} \mathrm{A}_{\mathrm{L}}$ " should be " $\mathrm{A}_{\mathrm{L}}$ "; 
Reply: Thanks for your useful comments. Required change is applied.

6. Page 9, Line 275, " $\mathrm{R}=4.3 \mathrm{Jmol}^{-1} \mathrm{~K}^{-1}$ ”, should it be “ $\mathrm{R}=8.31 \mathrm{Jmol}^{-1} \mathrm{~K}^{-1}$ ” ? Reply: Thanks for your useful comments. Required change is applied.

7. Page 33, lines 36 and 37, "ratio of volume during the regenerative processes" should be "ratio of volume during the isothermal processes" Reply: Thanks for your useful comments. All required changes are applied.

8. English and writing errors of the paper should be re-checked by an expert. Reply: Thanks for your useful comments. Required change is applied.

9. Quality of figures should be improved.

Reply: Thanks for your useful comments. All required changes are applied.

10. The performance analyses for Stirling cycles by using finite time thermodynamics (FTT) were also performed by other papers, the following papers concerning the progresses in FTT [1-7], FTT studies for Stirling cycle [8-12] should be included in this manuscript

[1]. Chen L G, Wu C, Sun F R. Finite time thermodynamic optimization or entropy generation minimization of energy systems. J. Non-Equilib. Thermodyn., 1999, 24(4): 327-359.

[2]. Wu C, Chen L G, Chen J C. Recent Advances in Finite Time Thermodynamics. New York: Nova Science Publishers, 1999.

[3]. Chen L G, Sun F R. Advances in Finite Time Thermodynamics: Analysis and Optimization. New York: Nova Science Publishers, 2004.

[4]. Chen L G. Finite-Time Thermodynamic Analysis of Irreversible Processes and Cycles. Beijing: High Education Press, 2005 (in Chinese).

[5]. Chen L G, Xia S J. Generalized Thermodynamic Dynamic-Optimization for Irreversible Processes. Beijing: Science Press, 2016 (in Chinese).

[6]. Chen L G, Xia S J, Li J. Generalized Thermodynamic Dynamic-Optimization for Irreversible Cycles. Beijing: Science Press, 2016 (in Chinese).

[7]. Ge Y L, Chen L G, Sun F R. Progress in finite time thermodynamic studies for internal combustion engine cycles. Entropy, 2016, 18(4): 139.

[8]. Wu F, Chen L G, Sun F R, Wu C, Zhu Y H. Performance and optimization criteria of forward and reverse quantum Stirling cycles. Energy Conversion and Management, 1998, 39(8): 733-739.

[9]. Wu F, Chen L G, Sun F R, Wu C. Finite-time exergoeconomic performance bound for a quantum Stirling engine. International Journal of Engineering Science, 2000, 38(2): 239247.

[10]. Wu F, Chen L G, Sun F R, Yu J Y. Finite Time Thermodynamic Optimization for Stirling Machines. Beijing: Chemical Industry Press, 2008.

[11]. Ding Z M, Chen L G, Sun F R. Performance optimization of a linear phenomenological law system Stirling engine. Journal of Energy Insitute, 2015, 88(1): $36-42$.

[12]. Yin Y, Chen L G, Wu F. Optimal power and efficiency of quantum Stirling heat engines. The European Physical Journal Plus, 2017, 132(1): 45. 


\section{Reply: Thanks for your useful comments. All required changes are applied.}

\section{Reviewer: 2}

In this manuscript, the authors used a MOPSO algorithm conjoint with Fuzzy, LINMAP and TOPSIS to optimize the Dish-Stirling solar system, based on the finite time thermodynamic model. Although the authors give a detailed explanation and description of the review work, this manuscript has some flaws as shown below, which negatively affect the quality of this work:

1) All the derived equations have to be checked carefully, especially the large ones. For instance, in Eq. (7) the "Tc" should be "Th"; in Eq. (32) the last "AR" should be multiplied by "AH".

Reply: Thanks for your useful comments. All required changes are applied.

2) In Lines 24 , Page 8 , it will be more logical that the new parameter " $A R=(A L / A H)$ " is moved to Line 51, Page 7.

Reply: Thanks for your useful comments. All required changes are applied.

3) In Section 5 "Decision making algorithm", it is key to determine the idea point, which is related to people preference [1], so the reviewer suggests to illustrate this problem clear.

Reply: Thanks for your useful comments. All required changes are applied.

4) In Lines 4-6, Page 15, please check the units of these parameters.

Reply: Thanks for your useful comments. All required changes are applied.

5) In Figs. 3-5, the legends are overlapped, which is avoidable by using arrows.

Reply: Thanks for your useful comments. All required changes are applied. 